\title{
Review
}

Xilu Chen, Xiaomin Li, Dandan Xu, Weichun Yang, and Shaoyuan Bai*

\section{Application of nanoscale zero-valent iron in hexavalent chromium-contaminated soil: $A$ review}

https://doi.org/10.1515/ntrev-2020-0059

received August 01, 2020; accepted August 08, 2020

\begin{abstract}
Chromium $(\mathrm{Cr})$ is a common toxic heavy metal that is widely used in all kinds of industries, causing a series of environmental problems. Nanoscale zero- valent iron (nZVI) is considered to be an ideal remediation material for contaminated soil, especially for heavy metal pollutants. As a material of low toxicity and good activity, nZVI has been widely applied in the in situ remediation of soil hexavalent chromium $(\mathrm{Cr}(\mathrm{vI}))$ with mobility and toxicity in recent years. In this paper, some current technologies for the preparation of nZVI are summarized and the remediation mechanism of $\mathrm{Cr}(\mathrm{VI})$-contaminated soil is proposed. Five classified modified nZVI materials are introduced and their remediation processes in $\mathrm{Cr}(\mathrm{VI})$-contaminated soil are summarized. Key factors affecting the remediation of $\mathrm{Cr}(\mathrm{vI})-$ contaminated soil by nZVI are studied. Interaction mechanisms between nZVI-based materials and $\mathrm{Cr}(\mathrm{vI})$ are explored. This study provides a comprehensive review of the nZVI materials for the remediation of $\mathrm{Cr}(\mathrm{VI})$-contaminated soil, which is conducive to reducing soil pollution.
\end{abstract}

Keywords: $\mathrm{Cr}(\mathrm{vI})$-contaminated soil, nanoscale zerovalent iron (nZVI), soil remediation, modified nano-iron

\footnotetext{
* Corresponding author: Shaoyuan Bai, Department of Environmental Engineering, College of Environmental Science and Engineering, Guilin University of Technology, Guilin, 541006, China, e-mail: baishaoyuan@163.com

Xilu Chen, Dandan Xu: Department of Environmental Engineering, College of Environmental Science and Engineering, Guilin University of Technology, Guilin, 541006, China

Xiaomin Li: Department of Environmental Engineering, School of Metallurgy and Environment, Central South University, Lushan South Road 932, Changsha 410083, China

Weichun Yang: Department of Environmental Engineering, School of Metallurgy and Environment, Central South University, Lushan South Road 932, Changsha Hunan 410083, China; Chinese National Engineering Research Center for Control \& Treatment of Heavy Metal Pollution, Lushan South Road 932, Changsha Hunan 410083, China
}

\section{Introduction}

Chromium (Cr) is one of the most common heavy metals, which are widely utilized in wood preservatives, metallurgy, chromium plating, chromate manufacturing, alloys, textiles, printing, dyeing, and other industrial manufacturing sectors [1]. Nevertheless, during these industrial production processes, a large amount of $\mathrm{Cr}$ gets released into soils, which brings about a series of environmental problems and arouses widespread concern [2].

In soils, $\mathrm{Cr}$ may be soluble in the solution, exchangeable on the solid phase, bound to organic substance or oxides and clay-like mineral, and trapped in a crystal lattice core [3]. The species of $\mathrm{Cr}$ mentioned above is related to its chemical form and is attributed to its bioavailability and toxicity. Cr has several oxidation states in the natural environment, the most common and stable of which in the environment and biosystem are $\mathrm{Cr}(\mathrm{III})$ and $\mathrm{Cr}(\mathrm{VI})$ [3].

$\mathrm{Cr}(\mathrm{III})$ is an essential trace element for human nutrition and has low toxicity [4]. It is easy to be hydrolyzed in aqueous solution, usually in the form of precipitates (i.e., $\mathrm{Cr}$ $(\mathrm{OH})_{3}$ and $\left.\mathrm{Cr}_{2} \mathrm{O}_{3}\right)$ in an alkaline or even in a weakly acidic environment, as shown in the Eh-pH diagram of $\mathrm{Cr}$ in solution (Figure 1) [5]. In contrast, $\mathrm{Cr}(\mathrm{VI})$ is soluble in water over a wide $\mathrm{pH}$ range, mainly in the form of hydrogen-chromate ion $\left(\mathrm{HCrO}_{4}^{-}\right)$under acidic conditions or in the form of chromate ion $\left(\mathrm{CrO}_{4}^{2-}\right)$ under neutral and alkaline conditions [6]. Therefore, the bioavailability of $\mathrm{Cr}(\mathrm{vI})$ is higher than that of $\mathrm{Cr}$ (III) since it is hard to be precipitated or adsorbed on soil colloids. Besides, $\mathrm{Cr}(\mathrm{vI})$ is also known as a strong oxidant and has a 400-fold higher toxicity than $\mathrm{Cr}$ (III) [7]. It is one of the 17 most dangerous toxic substances and a Class A carcinogen [8]. In addition, according to a document released by the United States Environmental Protection Agency [9], $\operatorname{Cr}(\mathrm{vI})$ is identified as the most important hazardous pollutant [10].

The $\mathrm{Cr}(\mathrm{vI})$ pollution in the soil is mainly caused by an unlawful leakage and illegal dumping of the chromium residue of industries. Once $\mathrm{Cr}(\mathrm{vi})$ enters the food chain 


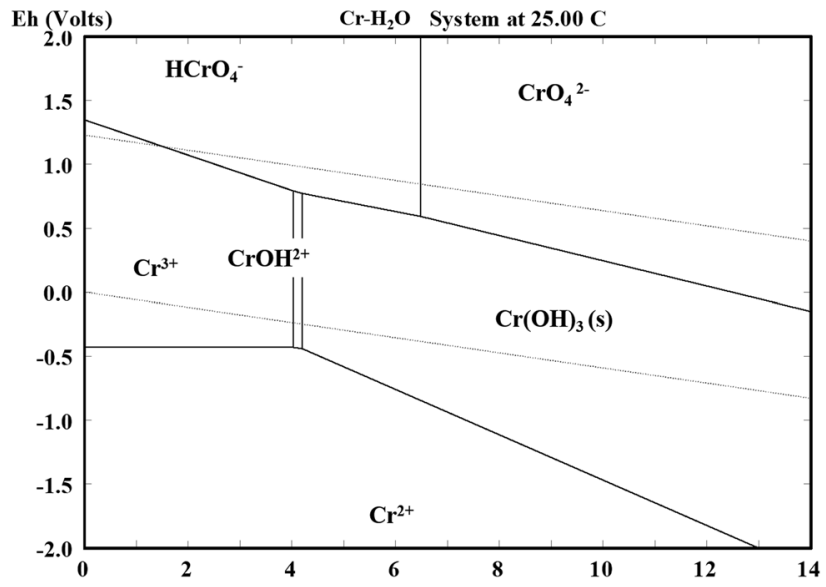

Figure 1: Eh-pH diagram of $\mathrm{Cr}$ in the solution [3].

through plants [11], it will be detrimental to the ecological environment, and eventually, pose a potential threat to the health of human and other living organisms, due to its mutagenicity, teratogenicity [6], and carcinogenicity [12]. Therefore, how to eliminate the $\mathrm{Cr}(\mathrm{vI})$ pollution in the soil has become a high-profile issue [13].

Several approaches have been exploited to remediate $\mathrm{Cr}(\mathrm{vI})$ contamination and they can be divided into in situ remediation and ex situ remediation. Ex situ remediation refers to the excavation and treatment of the polluted soil at the contaminated site [14]. Ex situ remediation, however, will significantly increase the transportation cost, and there is also a risk of pollutant diffusion during transportation and transfer. Technologies for in situ remediation [15], such as phytoremediation, bacterial remediation, chemical flushing, and chemical reduction [16], are more promising because of the lower cost and higher efficiency [17]. Moreover, soil disturbance can be minimized, which is better for the subsequent application of soil. Nevertheless, these in situ technologies [18] inevitably have shortcomings, such as long remediation period, difficult operation, unstable effects, and secondary pollution [19], which will limit their practical applications. Because the bioavailability and toxicity of $\mathrm{Cr}$ depend on its chemical form, the reduction of $\mathrm{Cr}(\mathrm{VI})$ to $\mathrm{Cr}(\mathrm{III})$ is an important process for $\mathrm{Cr}$ (vI)-contaminated soil remediation, as shown in the following reaction [5].

$$
\mathrm{CrO}_{4}^{2-}+6 \mathrm{e}+14 \mathrm{H}^{+} \leftrightarrow 2 \mathrm{Cr}^{3+}+7 \mathrm{H}_{2} \mathrm{O}
$$

Experiments have proved that $\mathrm{Cr}(\mathrm{vI})$ can be reduced to $\mathrm{Cr}$ (III) by the common wood preservative solution of chromate copper arsenate and three soil types (sandy soil, organic soil, and clayey soil) [20]. In addition, adding calcium polysulfide [21] or acidified hydrazine hydrate [13] can also reduce the content of hexavalent chromium in soil. Nevertheless, these materials are still not the most ideal due to various defects.

Nowadays, nanotechnology and nanomaterials have showed great potential to solve the water, air, and soil pollution problems [22,23]. In recent years, the application of nanoscale zero-valent iron (nZVI) in the in situ remediation of $\mathrm{Cr}(\mathrm{VI})$-contaminated soil has attracted extensive attention [24]. nZVI is a kind of material, which is generally in powder form, and its particle size generally lies within the range of $10-100 \mathrm{~nm}$ [25]. The original nZVI was prepared by reducing iron [26] with $\mathrm{NaBH}_{4}$, and in the laboratory [27], the original nZVI was synthesized by reducing $\mathrm{FeCl}_{3}$ with $\mathrm{NaBH}_{4}$. Furthermore, the production of nanocomposites with controllable shapes, sizes, and surface properties is important for different practical applications [28]. nZVI is a promising in situ remediation material [29] with a flexible particle size, a large specific surface area [30], fast reaction speed, a strong reduction ability, and an ideal cost-effectiveness [31]. Moreover, nZVI can effectively overcome the shortcomings of in situ remediation, such as long repair cycle and unstable effect. Therefore, it is an ideal repair material and has been widely applied to the in situ remediation of heavy metal pollutants as a reaction medium [32]. Nevertheless, the current research works on the treatment of $\mathrm{Cr}(\mathrm{VI})$ by nZVI are mainly concentrated in the water field, and there has been little progress in research works in the soil field in recent years.

In this paper, applications of nZVI in $\mathrm{Cr}(\mathrm{vI})$ contaminated soil remediation are comprehensively introduced. First, the synthesis and properties of nZVI are briefly introduced. Moreover, some typical methods for nZVI application in $\mathrm{Cr}(\mathrm{vI})$-polluted soil remediation and their influencing factors are summarized and evaluated. Furthermore, the basic remediation mechanisms of nZVI application in $\mathrm{Cr}(\mathrm{vI})$-contaminated soil are explored. Finally, some suggestions for potential remediation technologies are proposed.

\section{$2 \mathrm{nZVI}$ for the remediation of $\mathrm{Cr}$ (vi)-contaminated soil}

\subsection{Preparation and properties of $\mathrm{nZVI}$}

Nowadays, nanomaterials are widely applied in pollution control. Extensive studies have been carried out on nanomaterials, especially the correlation between the 
properties of nanomaterials and their chemical or physical properties [33]. In the past decade, nZVI has been used for the treatment of various common environmental pollutants existing in contaminated soil [34], groundwater and wastewater [35], such as chlorinated organic solvents, polychlorinated biphenyls, organochlorine pesticides [36], and heavy metal inorganic anions [37]. Due to its large surface area [38], fast reaction speed, and a strong reduction ability, nZVI can be used as the reaction medium of $\mathrm{Cr}(\mathrm{vI})$, with prospects of wide application [39].

There are many methods for preparing nZVI. Physical methods, such as grinding, abrasion, and lithography, were initially used. Currently, homogeneous solution or gas nucleation, and phase separation or high-temperature annealing are also widely used [40].

In addition to the physical methods described above, the most commonly used method to obtain nZVI is chemical reduction for its simplicity. The product obtained by this method is characterized by the uniform structure and high reaction activity. For example, sodium borohydride $\left(\mathrm{NaBH}_{4}\right)$ is used as the reducing agent [41], and nZVI is obtained by the following reaction [42]:

$$
\begin{gathered}
\mathrm{Fe}\left(\mathrm{H}_{2} \mathrm{O}\right)_{6}^{3+}+3 \mathrm{BH}_{4}^{-}+3 \mathrm{H}_{2} \mathrm{O} \rightarrow \mathrm{Fe}^{0} \downarrow+3 \mathrm{~B}(\mathrm{OH})_{3} \\
+10.5 \mathrm{H}_{2}
\end{gathered}
$$

Besides, there are still some less commonly used methods, such as precision grinding, carbothermal reduction, ultrasonic-assisted production, electrochemical generation, and green synthesis, whereas due to their advantages, they may become popular in the future [42].

\subsection{Classification and features of different modified nZVIs}

In the application of nZVI, the surface quality and structure of nZVI undoubtedly play a key role in its function [43]. However, pristine nZVI is thermodynamically unstable due to its small size, large surface energy, and surface curvature [44]. nZVI particles tend to aggregate and react quickly with non-target compounds in the surrounding media, which may reduce the activity and stability of nZVI. Each particle has a magnetic field. So, it produces a magnetic field and the particles get stuck in an agglomerated form. Therefore, some nZVI-based materials have been fabricated to remove the pollutants from the environment [25]. The common modified nZVI morphologies are shown in Figure 2(a). nZVI can be divided into organic modified nZVI, bimetallic modified nZVI, and materials loaded on modified nZVI.

\subsubsection{Organic modified $n Z V I$}

The interaction of organic matter with nano-iron can reduce the gravity of nano-iron particles, prevent the agglomeration of nano-iron particles, and improve the dispersion performance [45].

\subsubsection{Carboxymethyl cellulose (CMC)-supported nzVI}

Figure 2(b) shows the TEM image of CMC-nZVI. Among the modified materials of nZVI, CMC is inexpensive and environment-friendly. The use of CMC-stabilized nZVI can improve the fluidity and diffusion of nanoscale zerovalent iron particles; thus, CMC-stabilized nZVI is especially suitable for in situ remediation of chromiumcontaminated soil $[46,47]$.

The CMC-stabilized nZVI is prepared by the sodium borohydride reduction method from steel pickling wastewater. The specific synthesis steps are as follows: first, CMC is dissolved in deionized water, the diluted waste liquid is sucked out by purging with purified nitrogen, and then the environment is kept as anaerobic. Finally, the sodium borohydride solution is added dropwise during violent mixing of the mixture to obtain the stable CMC-stabilized nZVI [48].

Some studies have observed the TEM images of CMC-nZVI [49]. It is found that the size of CMC-nZVI is large, and the particle size is generally distributed between 80 and $120 \mathrm{~nm}$. The particles are not in chain structure, but are more evenly distributed. This shows that the CMC can effectively prevent the aggregation of nZVI nanoparticles [46].

\subsubsection{Vinegar residue (VR) supported nZVI}

Vinegar residue is composed of by-products and additives (rice bran, bran, and sorghum husk) produced by vinegar fermentation. According to the study of Pei et al. [32], VR is rich in such organic acids as acetic acid, malic acid, lactic acid, and tartaric acid. Figure 2(c) shows the SEM image of VR-nZVI.

The nZVI supported on a VR (nZVI@VR) is prepared in the following steps. First, ferrous sulfate and VR are stirred in rotating magnetic field at room temperature, and then the potassium borohydride $\left(\mathrm{KBH}_{4}\right)$ solution is added slowly 


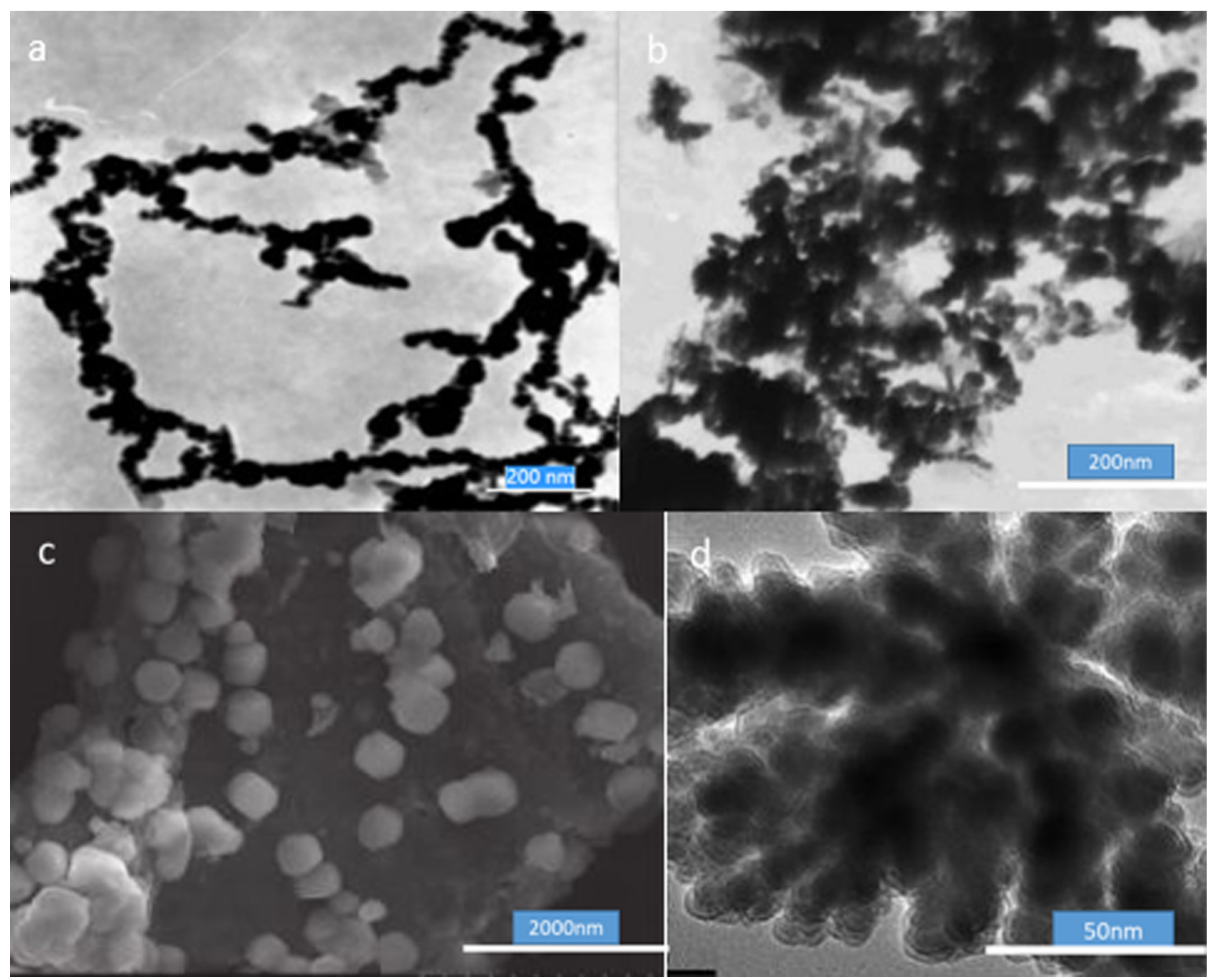

Figure 2: TEM image of nZVI. (a) [46]; TEM image of CMC-nZVI (b) [46]; SEM image of VR-nZVI (c) [32]; TEM images of Fe ${ }^{0}-C u$ (d) [56].

while stirring. Subsequently, nZVI@VR samples are separated from the mixture by vacuum filtration and finally dried in vacuum. It should be noted that in order to ensure that the nZVI@VR sample is not oxidized, nitrogen should be injected continuously during the process [32].

The feasibility of loading nZVI on VR composite to eliminate $\mathrm{Cr}(\mathrm{VI})$ in soil is tested by the settlement experiment. The results show that loading nZVI on VR could avoid aggregation and maintain the reactivity of particles. Furthermore, VR has a positive impact on soil properties and thus can be employed to improve soil pollution properties [32].

\subsubsection{Rice husk-derived biochar-supported nZVI}

It is a simple and economical one-step reduction method to directly use waste rice husk as the carrier of iron salt and the source of reducing agent. Using the polarity and hydrophilicity of carbon materials can reduce the energy consumption and reduce the adverse effects of biochar recarbonization [50], so that the waste rice husk can be fully reused.

The production process can be summarized as follows. First, nitrogen is introduced as the protective gas in the production process, then the rice husk is mixed with $\mathrm{Fe}_{2}\left(\mathrm{SO}_{4}\right)_{3}$ solution under specific pressure. The excess iron salt is filtered and washed out under vacuum after vibration, and finally the target sample is obtained [39].

\subsubsection{Other organics-supported nZVI}

In addition, chitosan [51] can form nanocomposites with other materials through electrostatic interaction [52], covalent crosslinking, macromolecular compounding, adsorption, 
and hydrogen bonding. Sucrose, vegetable oil, green tea, biochar [53], MCM-41 [54], and other extracts [55] can also be used as nZVI composite materials [21]. However, these materials were rare and less successful in treating $\mathrm{Cr}(\mathrm{VI})$, so they are not described in detail here.

\subsubsection{Bimetallic modified nZVI}

It has been proved that an additional metal material on the surface of nZVI can accelerate its reduction rate and effectively improve its performance [57]. The reaction activity of bimetallic particles is higher than that of nZVI [58]. Bimetallic modified nano-iron can delay the oxidation rate of $\mathrm{nZVI}$ and accelerate the reduction rate. There are many kinds of bimetallic modified materials [59], such as nano Ni/Fe bimetallic [60], nano $\mathrm{Cu} / \mathrm{Fe}$ bimetallic [56], nano $\mathrm{Pd} / \mathrm{Fe}$ bimetallic [61], nano Fe/Au bimetallic [62], and so on [63]. In this paper, the nano $\mathrm{Cu} / \mathrm{Fe}$ bimetallic material $\mathrm{nZVI} / \mathrm{Cu}$ is introduced. The TEM image of $\mathrm{Fe}^{0}-\mathrm{Cu}$ is shown in Figure 2(d).

nZVI/Cu is synthesized by dissolving $\mathrm{FeCl}_{3} \cdot 6 \mathrm{H}_{2} \mathrm{O}$. At room temperature and under nitrogen gas condition, $\mathrm{CuSO}_{4}$ is put into alcohol and stirred continuously. $\mathrm{NaBH}_{4}$ is dissolved in deionized water. The mixture is added and stirred vigorously. After stirring, the black solid particles are obtained. Subsequently, they are pumped and filtered, then washed with deionized water and ethanol, and finally sent to the vacuum dryer for drying [64].

\subsubsection{Materials loaded on modified nZVI}

Bentonite is a nZVI-loading material. It is a kind of silicate with a sheet structure, is non-toxic, offers environmental protection, and holds abundant reserves. When the bentonite is used as the support material of nZVI, a large amount of nZVI can be adsorbed on the surface of nZVI itself, which can promote the dispersion of nZVI particles and reduce their agglomeration. Thus, the final composite nZVI has a very good adsorption performance and improves the decontamination ability of nZVI [65]. Figure 3 shows the structure and morphology of nZVI@Bent's.

The study of Leupin et al. [65] introduces the preparation method. The specific steps are as follows. Under the protection of nitrogen, the solid with the mass ratio of $\mathrm{Fe}^{2+}$ to bentonite of $1: 1$ is weighed and added with $\mathrm{FeSO}_{4} \cdot 7 \mathrm{H}_{2} \mathrm{O}$ to the mixture of quantitative absolute ethanol and ultrapure water, and stirred. During continuous stirring, $2 \mathrm{~mol} / \mathrm{L}$ of $\mathrm{NaBH}_{4}$ solution is added into the mixture. Finally, the target sample is prepared by vacuum filtration, fast rinsing with absolute ethanol, and drying in vacuum drying oven (Table 1).

\section{Remediation of $\mathrm{Cr}(\mathrm{v} \mathrm{r})$ - contaminated soil by nZVI}

In the process of remediation of $\mathrm{Cr}(\mathrm{vI})$-contaminated soil by nZVI, in order to prevent iron agglomeration as well as to improve the remediation efficiency of nZVI, modified materials are generally used to stabilize nZVI, including CMC-stabilized nZVI, nZVI@VR, and nZVI-RBC. Various tests were performed to evaluate the remediation effect of $\mathrm{Cr}(\mathrm{vI})$-contaminated soil from different aspects. The $\mathrm{Cr}(\mathrm{vI})$ will adsorb on nZVI, through the surface pores and oxygen-containing functional

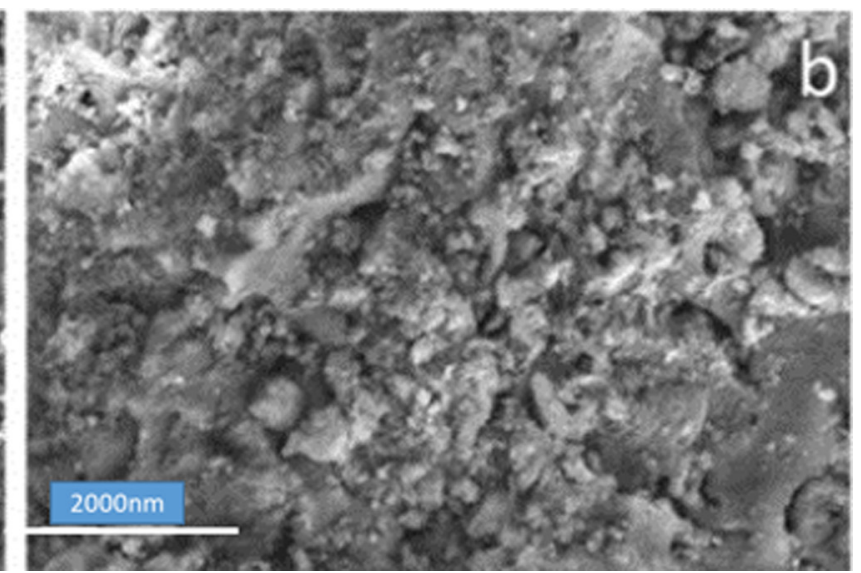

Figure 3: nZVI@Bent before reaction (a); nZVI@Bent after reaction (b) [66]. 
groups, and then react directly with the surface to reduce to $\mathrm{Cr}(\mathrm{III})$, whereas nZVI is oxidized to $\mathrm{Fe}^{2+}$ and indirectly reduced with $\mathrm{Cr}(\mathrm{vI})$ [66]. For example, toxicity characteristic leaching procedure is used to examine the leaching ability of $\mathrm{Cr}$, and the immobilization and bioaccumulation of $\mathrm{Cr}$ in the improved soil are discussed through in vitro and plant experiments [67].

\subsection{Remediation of $\mathrm{Cr}(\mathrm{vI})$-contaminated soil by CMC-stabilized nZVI}

In vitro and plant experiments show that the application of CMC-nZVI to remove $\mathrm{Cr}(\mathrm{vI})$ from contaminated soil can significantly enhance the immobilization of $\mathrm{Cr}$ by converting $\mathrm{Cr}(\mathrm{VI})$ to $\mathrm{Cr}(\mathrm{III})$ [15], thereby reducing its bioavailability, leaching ability, and plant bioaccumulation, and finally realize the remediation of $\mathrm{Cr}(\mathrm{vI})$ contaminated soil [46].

As suggested by Zhang et al. [46], the speciation of $\mathrm{Cr}$ in soil changes from relatively high availability (exchangeable) to relatively lower availability (carbonate binding and iron manganese oxide binding). The results show that $\mathrm{Cr}(\mathrm{OH})_{3}$ or $\mathrm{Cr}(\mathrm{III}) / \mathrm{Fe}(\mathrm{III})$ hydroxides are the main forms of $\mathrm{Cr}(\mathrm{OH})_{3}$ or $\mathrm{Cr}(\mathrm{III}) / \mathrm{Fe}(\mathrm{III})$ hydroxides [68]. After the application of modified nZVI, $\mathrm{Cr}(\mathrm{vI})$ are adsorbed and fixed by soil particles, so that the remediation of $\mathrm{Cr}(\mathrm{vI})$-contaminated soil is achieved.

The effects of biochar addition on CMC-nZVI and CMC-nZVI alone are compared. The results show that the conversion efficiency of $\mathrm{Cr}(\mathrm{vI})$ declines slightly, whereas the immobilization efficiency of total chromium increases. This is because biochar can adsorb a small amount of CMC-nZVI, which leads to a decrease in the effective contact area between nZVI and $\mathrm{Cr}$, thereby further reducing the conversion efficiency of $\mathrm{Cr}(\mathrm{vI})$. However, the reduction reaction after adding biochar [69] prolongs the total remediation time and increases the immobilization efficiency of total chromium [70].

CMC-nZVI has a significant effect on the remediation of $\mathrm{Cr}(\mathrm{vI})$-contaminated soil. nZVI modified by CMC and addition of biochar into CMC-nZVI can realize the remediation of $\mathrm{Cr}(\mathrm{vI})$-contaminated soil, and also greatly reduce the leaching of $\mathrm{Cr}$ in a contaminated soil by more than 95\%. Finally, the experimental results of Zhang et al. [46] show that when the content of $\mathrm{Cr}(\mathrm{vI})$ in

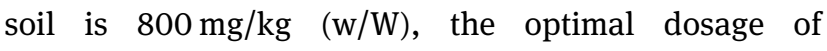
CMC-nZVI/BC for remediation of $\mathrm{Cr}(\mathrm{vI})$-contaminated soil is $11 \mathrm{~g} / \mathrm{kg}$. 


\subsection{Remediation of $\mathrm{Cr}(\mathrm{vl})$-contaminated soil by vinegar residue supported $\mathrm{nZVI}$}

The specific process of $\mathrm{Cr}(\mathrm{vI})$ immobilization by nZVI with VR (nZVI@VR) as support material is as follows. First, highly toxic $\mathrm{Cr}(\mathrm{vI})$ is adsorbed on the surface of nZVI@VR through the surface pores and oxygen-containing functional groups, such as $\mathrm{C}-\mathrm{O}, \mathrm{COO}-$, or $-\mathrm{OH}$. Then the content of $\mathrm{Cr}(\mathrm{VI})$ is reduced by the zero-valent iron. Finally, $\left(\mathrm{Cr}_{x} \mathrm{Fe}_{1-\chi}\right)(\mathrm{OH})_{3}$ and $\mathrm{Cr}_{x} \mathrm{Fe}_{1-x} \mathrm{OOH}$ are precipitated [71].

In the practical application of nZVI@VR, if the nZVI@VR powder is used as an improver, it is not easy to pack and will be blown away by the wind, which will negatively impact the health of people without a cover. Therefore,nZVI@VR powder needs to be transformed into a nZVI@VR particle.

The specific transformation process can be summarized as follows.nZVI@VR and attapulgite are mixed and water is added in proportion. The mixture is stirred until it is completely homogeneous.nZVI@VR particles are produced by a granulator at room temperature and air-dried at $50^{\circ} \mathrm{C}$.

After granulation, the granular nZVI@VR is used for remediation, and it is found that the conversion rate of the available $\mathrm{Cr}$ to low-availability components is accelerated, significantly reducing the bioavailability of $\mathrm{Cr}$.

The results of Pei et al. [27] show that the fixation efficiency of nZVI@VR without granulation is 98.68\%. When the content of $\mathrm{Cr}(\mathrm{vI})$ in soil is $198.20 \mathrm{mg} / \mathrm{kg}$, the best dosage of nZVI@VR is $50 \mathrm{~g} / \mathrm{kg}$, i.e., 5\%.

\subsection{Remediation of $\mathrm{Cr}(\mathrm{vI})$-contaminated soil by rice husk-derived biochar- supported $\mathrm{nZVI}$}

In recent years, biochar has also been used as the carrier of nZVI for the reuse of waste biomass.

In order to remediate $\mathrm{Cr}(\mathrm{vI})$-contaminated soil, waste rice husk is used as an iron carrier and reductant [39]. When the main form of $\mathrm{Cr}$ in contaminated soil is acid soluble, it is found that during the reduction of $\mathrm{Cr}(\mathrm{vI})$ by nZVI-RBC, the redox products of $\mathrm{Fe}$ and $\mathrm{Cr}$ form, and the residual $\mathrm{Cr}$ in soil accounts for $47.5 \%, 24.6 \%$, and $27.9 \%$, respectively. $\mathrm{Cr}$ in soil is transformed into a low-bioavailability form, and the leaching of $\mathrm{Cr}$ is greatly inhibited. nZVI-RBC has long-term remediation ability to $\mathrm{Cr}(\mathrm{vI})$ contaminated soil.

The final experimental results show that when the concentration of $\mathrm{Cr}(\mathrm{VI})$ in the leachate is $62.4 \mathrm{mg} / \mathrm{L}$ and the dosages of modified nZVI are $8 \%$ and $12 \%$, respectively, in which case, the best remediation effect of $\mathrm{Cr}(\mathrm{vI})$-contaminated soil can be achieved. Under these two dosages, nZVI-RBC could completely remove $\mathrm{Cr}(\mathrm{vI})$ in 120 and $30 \mathrm{~min}$, respectively, and no $\mathrm{Cr}(\mathrm{VI})$ can be detected in the soil leachate for 6 consecutive days.

\subsection{Remediation of $\mathrm{Cr}(\mathrm{VI})$-contaminated soil by bimetallic-modified $n Z \mathrm{VI}$}

Copper-iron bimetallic particles can be formed by coating copper on the surface of nZVI. The study showed that compared with other oxidation pollutants, nZVI needs a higher copper content to remove $\mathrm{Cr}(\mathrm{vI})$. Under acidic conditions, $\mathrm{Cr}(\mathrm{vI})$ is further reduced by $\mathrm{Fe}^{2+}$ and $\mathrm{Cu}^{0}$ formed in the reaction of $\mathrm{nZVI} / \mathrm{Cu}$ and $\mathrm{Cr}(\mathrm{vI})$. The deposition of iron oxide on the surface of the material can be effectively inhibited, and the active sites on the surface of $\mathrm{nZVI} / \mathrm{Cu}$ can be exposed, and finally the reduction reaction of $\mathrm{Cr}(\mathrm{vI})$ is promoted.

The results show that when the contaminated soil contains $120 \mathrm{mg} / \mathrm{kg} \mathrm{Cr}(\mathrm{vI})$, the $\mathrm{Cr}(\mathrm{vI})$ reduction exceeded $99 \%$ at a $\mathrm{pH}$ of 5 , temperature of $303 \mathrm{~K}$, and $\mathrm{nZVI} / \mathrm{Cu}$ dose of $0.06 \mathrm{~g}$ [64].

\subsection{Remediation of $\mathrm{Cr}(\mathrm{vI})$-contaminated soil by bentonite-supported $\mathrm{nZVI}$}

In the process of remediation of $\mathrm{Cr}(\mathrm{vI})$-contaminated soil by nZVI@Bent [32], Cr(vI) will adsorb on nZVI and react directly with the surface containing nZVI to be reduced to $\mathrm{Cr}(\mathrm{III})$, while nZVI is oxidized to $\mathrm{Fe}^{2+}$ and indirectly reduced with $\mathrm{Cr}(\mathrm{VI})$ [72].

The experimental results of Leupin et al. [65] show that when the ratio of iron to bentonite is $1: 0.5$ and the dosage is $5 \mathrm{~g} / \mathrm{L}$, the removal rate of $\mathrm{Cr}(\mathrm{vI})$ in the soil suspension is the highest, which is the best reaction condition for removing $\mathrm{Cr}(\mathrm{vI})$ (Table 2).

\section{Factors affecting the remediation of $\mathrm{Cr}(\mathrm{v} \mathrm{v})$-contaminated soil by $\mathrm{nZVI}$}

In the application of nZVI, there are many factors which will affect the removal effect, including the initial $\mathrm{pH}$ 


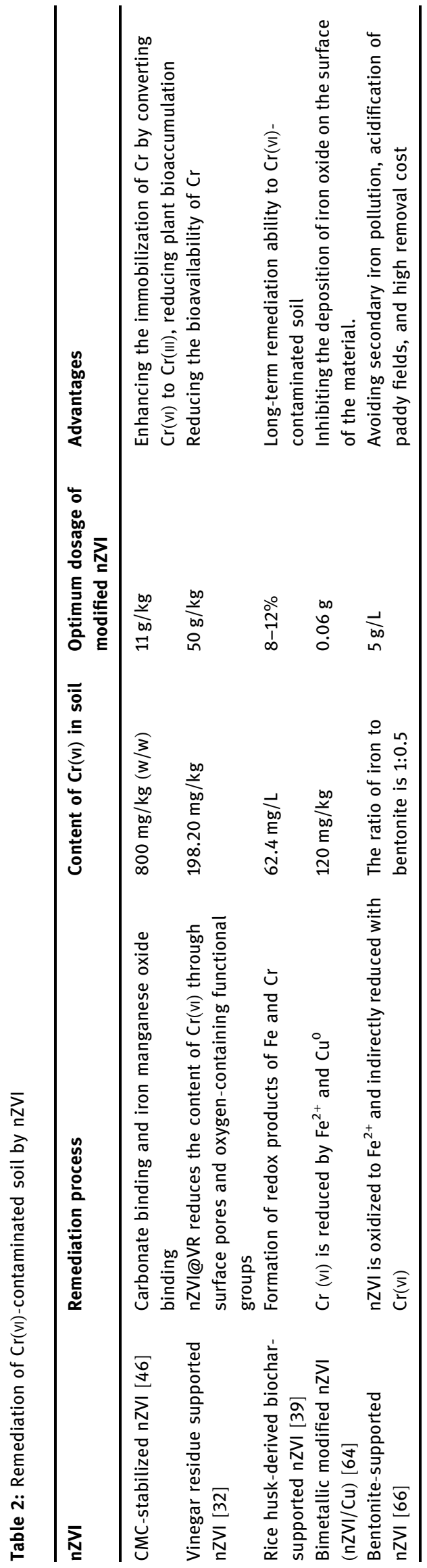

value, temperature, nZVI dosage, the chemical composition of surrounding organic matter, etc. [73].

\subsection{Effect of the initial pH value}

It is found that the initial $\mathrm{pH}$ value has a significant impact on the removal rate of $\mathrm{Cr}(\mathrm{vI})$ in soil, no matter what kind of nZVI is wrapped by modified materials [74]. More specifically, the $\mathrm{pH}$ value and the $\mathrm{Cr}(\mathrm{vI})$ removal rate show a negative correlation [75], that is, with the rising $\mathrm{pH}$ value, the $\mathrm{Cr}(\mathrm{vI})$ removal rate declines [76].

In the experiment of remediating $\mathrm{Cr}(\mathrm{vI})$-contaminated soil with nZVI and copper bimetallic particles, it is found that the $\mathrm{Cr}(\mathrm{vI})$ removal rate is much higher at $\mathrm{pH} 5$ than at $\mathrm{pH} 7$ or 9 , and the reduction rate could reach $99.9 \%$ within $5 \mathrm{~min}$. Due to the release of $\mathrm{Fe}^{2+}$ under acidic conditions, the deposition of iron oxide on the material's surface is well inhibited, the active sites on the surface of $\mathrm{nZVI} / \mathrm{Cu}$ are exposed, and the reduction rate of $\mathrm{Cr}(\mathrm{VI})$ is accelerated [77]. In an alkaline condition, however, owing to the precipitation of $n Z V I / C u$, a passivation layer is easily formed on the surface of $\mathrm{nZVI} / \mathrm{Cu}$, which hinders the contact between $\mathrm{nZVI} / \mathrm{Cu}$ and $\mathrm{Cr}(\mathrm{VI})$, and meanwhile affects the formation of the codeposition of ferrochromium, thereby lowering the reduction rate [64].

The reason is due to the fact that the acidic environment will corrode the oxide layer of $\mathrm{Fe}_{2} \mathrm{O}_{3}$ and FeOOH attached to the surface of nZVI@Bent, thereby exposing more reaction sites. A large amount of free $\mathrm{H}^{+}$ in the soil suspension promotes the reaction direction of nZVI removal, and the removal efficiency of $\mathrm{Cr}(\mathrm{vI})$ in soil is improved. Nevertheless, the contact between nZVI@Bent and $\mathrm{Cr}(\mathrm{vI})$ in an alkaline environment is reversed [65].

To sum up, the conclusion can be drawn that the soil is acidic, which is conducive to remediating $\mathrm{Cr}(\mathrm{vI})$ contaminated soil [78].

\subsection{Effect of the reaction temperature}

As a key factor, temperature has a profound influence on the $\mathrm{Cr}(\mathrm{VI})$ removal rate and chemical reaction rate [20]. It is found that the temperature and $\mathrm{Cr}(\mathrm{vI})$ removal rate are in a positive correlation, that is, the $\mathrm{Cr}(\mathrm{vI})$ removal rate increases with the rising temperature. 
After describing the reaction by the Langmuir-Hinshelwood first-order kinetic model or half-life, it can be concluded that the activation of reactant molecules increases as the temperature rises. That is, the reaction rate constant increases with the rising temperature. Some studies have confirmed that the concentration of $\mathrm{Cr}(\mathrm{vI})$ in soil should be reduced to the same concentration $(2 \mathrm{mg} / \mathrm{L})$, and it should be used for $30 \mathrm{~min}$ at $298 \mathrm{~K}$ and $10 \mathrm{~min}$ at $303 \mathrm{~K}$. When the temperature is above $303 \mathrm{~K}$, the $\mathrm{Cr}(\mathrm{vI})$ removal rate continues to increase slowly [64].

In the experiment of nZVI@Bent materials mentioned above, it is found that with the increasing reaction temperature, the removal rate of $\mathrm{Cr}(\mathrm{vI})$ in soil solution by nZVI@Bent presents an ascending trend. The specific reason is that after the temperature rises, the energy in the reaction system increases correspondingly; thus, the number of reaction molecules increases and the reaction rate accelerates [66].

To sum up, with the increase of reaction temperature, the reaction will advance backward, which is conducive to accelerating the remediation of $\mathrm{Cr}(\mathrm{vI})$ contaminated soil $[64,79]$.

\subsection{Effect of other factors}

In addition to $\mathrm{pH}$ and temperature, there are many other factors that affect the $\mathrm{Cr}(\mathrm{vI})$ removal rate [80]. For example, the dosage of nZVI [81], the contact time between nZVI and soil environment, the concentration of nZVI, the initial concentration of $\mathrm{Cr}(\mathrm{vI})$, and the chemical composition of surrounding organic matter, heavy metal, ion species, and other media will impact the reaction rate [82].

The results show that when the amount of nZVI increases, the active molecules will increase as well [26], and a large amount of $\mathrm{Cr}(\mathrm{vI})$ will adhere to the nZVI particles, resulting in a higher reaction rate [83].

In addition, the concentration of $\mathrm{Cr}(\mathrm{vI})$ is inversely proportional to the removal rate of $\mathrm{Cr}(\mathrm{vI})$. Under high $\mathrm{Cr}(\mathrm{vI})$ concentration, the immobilization efficiency of $\mathrm{Cr}$ (III) in the reduced soil liquid phase is low, and the surface area of nZVI is limited. In this case, there isn't enough position for excess $\mathrm{Cr}(\mathrm{III})$, which leads to the slow removal rate of $\mathrm{Cr}(\mathrm{vI})$ [66].

It should be pointed out that there are many factors affecting the $\mathrm{Cr}(\mathrm{vI})$ removal rate, and the combination of each factor is more complex than that of the current one, which needs to be analyzed in detail [65].

\section{Interaction mechanism between nZVI-based materials and $\mathrm{Cr}(\mathrm{VI})$}

In the treatment of $\mathrm{Cr}(\mathrm{vI})$-contaminated soil, nZVI-based materials have been widely studied and show great potential and broad application, as mentioned above.

The methods and applications of various modified nZVIs for the remediation of $\mathrm{Cr}(\mathrm{vI})$-contaminated soil have been introduced. According to these introductions, many researchers have speculated and verified the mechanism, but the systematic summaries are few. The mechanisms of these methods can be divided into adsorption mechanism and reduction mechanism.

\subsection{Reduction mechanism}

In fact, the major removal mechanism of nZVI on $\mathrm{Cr}(\mathrm{vI})$ in soil is reduction [84]. It is found that the removal of heavy metal ions is generally attributed to the reduction process when nZVI is used as the repair material [85]. The reduction of $\mathrm{Cr}(\mathrm{vI})$ by zero-valent iron is a multistep process, in which the zero-valent iron acts as an electron donor of heavy metal ions [86].

According to the theme of this paper, the process of $\mathrm{Cr}$ (vi) reduction in soil can be classified into direct reduction and indirect reduction. The final products from reduction are $\mathrm{Cr}(\mathrm{OH})_{3}$ and $\mathrm{Fe}(\mathrm{III})-\mathrm{Cr}(\mathrm{III})$ complexes [66].

First, in the process of direct reduction, $\mathrm{Cr}(\mathrm{VI})$ in soil adsorbs on the curved surface of nZVI and reacts directly with the surface containing nZVI to form Cr(III) [87]; second, in the indirect reduction process, nZVI will be oxidized to $\mathrm{Fe}^{2+}$ first [88], and to $\mathrm{Fe}^{3+}$ subsequently [89], both with the reduction from $\mathrm{Cr}(\mathrm{VI})$ to $\mathrm{Cr}(\mathrm{III})$. $\mathrm{Cr}$ (III) will combine with $\mathrm{OH}^{-}$and $\mathrm{Fe}^{3+}$, to form $\mathrm{Cr}(\mathrm{OH})_{3}$ and $\mathrm{Fe}(\mathrm{III})-\mathrm{Cr}(\mathrm{III})$ complexes [66].

In addition, when $\mathrm{Cr}(\mathrm{vI})$ is present in the curved particle system and soil suspension, the reduction process is stronger than the adsorption process. In the process of $\mathrm{Cr}(\mathrm{vI})$ reduction, most of the $\mathrm{Cr}(\mathrm{vI})$ will be removed, accordingly, the residual $\mathrm{Cr}(\mathrm{vI})$ in soil will be reduced [90].

The specific reaction is as follows [91]. (1) $\mathrm{Cr}(\mathrm{VI})$ was adsorbed on the surface of nZVI through surface pores and oxygen-containing functional groups. (2) $\mathrm{Cr}(\mathrm{vI})$ in soil was reduced by $\mathrm{FeO}$ (equations (3)-(5)). (3) Precipitation of $\left(\mathrm{Cr}_{x} \mathrm{Fe}_{1-\chi}\right)(\mathrm{OH})_{3}$ and $\mathrm{Cr}_{x} \mathrm{Fe}_{1-x} \mathrm{OOH}$ (equations (6) and (7)): 


$$
\begin{array}{r}
2 \mathrm{HCrO}_{4}^{-}(\mathrm{aq})+3 \mathrm{Fe}^{0}(\mathrm{~s})+14 \mathrm{H}^{+}(\mathrm{aq}) \rightarrow 3 \mathrm{Fe}^{2+}(\mathrm{aq}) \\
+2 \mathrm{Cr}^{3+}(\mathrm{aq})+8 \mathrm{H}_{2} \mathrm{O}(\mathrm{l}) \\
\mathrm{HCrO}_{4}^{-}(\mathrm{aq})+3 \mathrm{Fe}^{2+}(\mathrm{aq})+3 \mathrm{H}^{+}(\mathrm{aq}) \rightarrow 3 \mathrm{Fe}^{2+}(\mathrm{aq}) \\
+\mathrm{Cr}^{3+}(\mathrm{aq})+2 \mathrm{H}_{2} \mathrm{O}(\mathrm{l}) \\
3 \mathrm{Fe}^{2+}(\mathrm{aq})+\mathrm{CrO}_{4}^{2-}(\mathrm{aq})+8 \mathrm{H}^{+}(\mathrm{aq}) \rightarrow 3 \mathrm{Fe}^{2+}(\mathrm{aq}) \\
+\mathrm{Cr}^{3+}(\mathrm{aq})+4 \mathrm{H}_{2} \mathrm{O}(\mathrm{l}) \\
(1-x) \mathrm{Fe}^{2+}(\mathrm{aq})+(x) \mathrm{Cr}^{3+}(\mathrm{aq})+3 \mathrm{H}_{2} \mathrm{O}(\mathrm{aq}) \\
\rightarrow\left(\mathrm{Cr}_{x} \mathrm{Fe}_{1-x}\right)(\mathrm{OH})_{3}(0<x<1)(\mathrm{s})+3 \mathrm{H}^{+}(\mathrm{aq}) \\
(1-x) \mathrm{Fe}^{2+}(\mathrm{aq})+(x) \mathrm{Cr}^{3+}(\mathrm{aq})+2 \mathrm{H}_{2} \mathrm{O}(\mathrm{aq}) \\
\rightarrow\left(\mathrm{Cr}_{x} \mathrm{Fe}_{1-x}\right) \mathrm{OOH}(0<x<1)(\mathrm{s})+3 \mathrm{H}^{+}(\mathrm{aq})
\end{array}
$$

On the other hand, zero-valent iron and $\mathrm{Cr}(\mathrm{vI})$ can also carry out charge transfer through biochar to maintain the redox reaction, but the difference is that in this process, the removal rate of hexavalent chromium in soil is relatively low [39].

\subsection{Adsorption mechanism}

Compared with other methods, adsorption method is simple and efficient, thus it is the most commonly used technology for organic pollutants' removal [92]. Due to the rich oxygen-containing functional groups on the surface of various adsorbents [93], adsorption technology is considered to be a typical reaction process for removing $\operatorname{Cr}(\mathrm{vI})$ and other heavy metal ions [94]. The adsorption performance of adsorbents depends on the morphology and structure of porous materials, such as specific surface area, pore volume, pore distribution, and special pore surface chemistry [92]. The main principle of adsorption is related to the large specific surface area of nZVI and adsorption sites on its surface [95]. It has been proved that nZVI-based materials physically [96] contain a large number of active sites or functional groups [97].

Based on the analysis of the results and material characterization of the removal of $\mathrm{Cr}(\mathrm{vI})$ by $\mathrm{nZVI}$ (nZVI-RBC) supported by biochar, the reaction mechanism can be inferred as follows: on the surface of biochar, when $\mathrm{CrO}_{4}^{2-}$ diffuses to the surface of nZVI-RBC in the reaction system, some ions unite with the function and react with nZVI [98], $\mathrm{CrO}_{4}^{2-}$. On the one hand, the electrons provided by the zero-valent iron can be directly obtained and will be oxidized into ferrous iron and trivalent iron. At this time, $\mathrm{CrO}_{4}^{2-}$ combined with functional groups will be gradually reduced to trivalent chromium, so the concentration of $\mathrm{Cr}(\mathrm{vI})$ in soil will be rapidly reduced [39].

In addition, part of biochar as modified material will be dissolved to form dissolved organic carbon, and part of $\mathrm{Cr}(\mathrm{VI})$ will be reduced to $\mathrm{Cr}$ (III). The dissolution of biochar also results in the lack of coating materials for nZVI; thus, nZVI is gradually exposed to the reaction system and could directly participate in the reduction of $\mathrm{Cr}(\mathrm{vI})$. Despite the fact that these processes are much slower than other processes, they are still a continuous and effective way to remediate $\mathrm{Cr}(\mathrm{VI})$-contaminated soil [30].

In fact, the position of nZVI reaction surface may be the corrosion products of stable or metastable iron (II), mixed iron (II)/(III), or iron (III) oxide, hydroxide, or hydroxide. These iron hydroxide and oxide could enhance their adsorption capacity under natural environment [39].

During adsorption, the $\mathrm{Cr}(\mathrm{vI})$ in the soil can be directly adsorbed by nZVI, and the $\mathrm{Cr}(\mathrm{OH})_{3}$ and $\mathrm{Fe}$ (III)-Cr(III) complexes produced in the reduction process described later will also be adsorbed by nZVI. Through the above process, $\mathrm{Cr}(\mathrm{vI})$ pollution in the soil will be further reduced [66].

After the synthesis of microcrystalline cellulose (MCC) immobilized nZVI (c-nZVI), the reductive adsorption of $\mathrm{Cr}(\mathrm{vI})$ on MCC is studied. nZVI adsorbs $\mathrm{Cr}(\mathrm{vI})$ to $\mathrm{Fe}$ (III) by zero-valent iron redox. $\mathrm{Fe}(\mathrm{III})$ is reduced and regenerated to zero-valent iron by the in situ oxidation of cellulose to cellulose dialdehyde [99].

\subsection{Other interaction mechanism}

More occasionally, van der Waals force, magnetic force, specific surface bonding, and electrostatic interaction control the main mechanism in some natural environmental reaction systems [100].

In addition, the coprecipitation theory can also support the remediation mechanism of $\mathrm{Cr}(\mathrm{VI})$-contaminated soil by nZVI or nZVI-modified materials. When $\mathrm{Fe}^{2+}$ reduces $\mathrm{Cr}$ (VI) in the soil suspension to $\mathrm{Cr}(\mathrm{III}), \mathrm{Cr}(\mathrm{III})$ can combine with $\mathrm{OH}^{-}$in the soil suspension to form $\mathrm{Cr}$ $(\mathrm{OH})_{3}$, while $\mathrm{Fe}^{2+}$ is oxidized to $\mathrm{Fe}^{3+}$, and $\mathrm{Fe}^{3+}$ combines with free $\mathrm{OH}^{-}$to form $\mathrm{Fe}(\mathrm{OH})_{3}$. Finally, both of them combine with $\mathrm{Cr}(\mathrm{III})$ in the soil suspension to form a $\mathrm{Fe}(\mathrm{III})-\mathrm{Cr}(\mathrm{III})$ complex to remediate $\mathrm{Cr}(\mathrm{VI})$-contaminated soil [101]. 


\section{Future prospective and conclusions}

In the practical application of nZVI to repair $\mathrm{Cr}(\mathrm{vI})$, in addition to its advantages, there are some disadvantages as well. Pure nZVI is easy to agglomerate and passivate. Besides, it has poor transport capacity and can reduce electron transfer, which will weaken its remediation effect [46]. Although the modified nZVI can avoid some of the above problems, it also gives rise to some other new problems. For example, it may inhibit the reaction between nZVI and target pollutants or cause other new environmental pollution problems. Many modified materials can be prepared only under extremely strict conditions. Some of them are easy to oxidize and difficult to preserve, and the reduction selectivity of the nanoscale zero-valent iron is poor. For example, the use of sulfidation [88]-modified materials may induce corrosion of the nZVI core and increase the particle size. The application of bimetallic particles [64] as modified materials is also likely to increase corrosion, reduce the service life of nZVI, and even introduce other heavy metals, resulting in a serious environmental pollution. If borohydride is used as a common reducing agent, the cost of wet synthesis method is too high to be used on a large scale and may cause secondary pollution [32]. These are the problems that need to be addressed at present or they will hinder the further development of nZVI to a certain extent [102].

In order to make the nZVI system fully competitive, major improvements and upgrades should be carried out. First of all, the reaction between nZVI and soil pollutants is very complex [103], and its remediation efficiency needs improvement [104]. Therefore, the research work on its reaction mechanism, such as the possible properties of soil itself [105], the potential impact of nZVI on soil pollutants [106], and the influence of combined application of nZVI and biotechnology on soil remediation, should be further studied.

Second, although nZVI has been widely used, its preparation method is too complex and time-consuming, so the cost is high. Thus, in order to prepare nZVI on a large scale, it is necessary to explore new preparation methods to obtain nZVI with higher quality and performance at the lowest cost [107]. Future research works must seek to establish a sound evidence system, on which one can accurately predict the liquidity, responsiveness, fate, and ecological impact of nZVI [35].

In addition, due to the complexity and variability of the natural environment [108], most application sites of
nZVI are carried out only on the laboratory scale, and field applications are lacking. Furthermore, other models are needed to detect the potential risks of nZVI to plants and microorganisms [29] in the soil during pollutant remediation [109-112].

However, in general, nZVI is a very promising and widely used reductant, which can also be used in any other heavy metal remediation. The mechanism of nZVI repair is not only limited to reduction mechanism and adsorption mechanism, but also to oxidation mechanism. The oxidation mechanism is realized by the Fenton reaction, forming various derivatives of iron, oxidizing various target pollutants, and finally realizing the separation of heavy metal ions.

Acknowledgment: This work was supported by the Guangxi Science and Technology Base and Talent Special project (2019AC20023).

Conflict of interest: The authors declare no conflict of interest regarding the publication of this paper.

\section{References}

[1] Zhou X, Jing G, Lv B, Zhou Z, Zhu R. Highly efficient removal of chromium(vi) by $\mathrm{Fe} / \mathrm{Ni}$ bimetallic nanoparticles in an ultrasound-assisted system. Chemosphere. 2016;160:332-41.

[2] Lyu H, Tang J, Huang Y, Gai L, Zeng EY, Liber K, et al. Removal of hexavalent chromium from aqueous solutions by a novel biochar supported nanoscale iron sulfide composite. Chem Eng J. 2017;322:516-24.

[3] Ertani A, Mietto A, Borin M, Nardi S. Chromium in agricultural soils and crops: a review. Water Air Soil Pollut. 2017;228(5):190.

[4] Balmer J. Hexavalent chromium. Workplace Health Saf. 2018;66(11):564.

[5] Li Y, Wang W, Zhou L, Liu Y, Mirza ZA, Lin X. Remediation of hexavalent chromium spiked soil by using synthesized iron sulfide particles. Chemosphere. 2017;169:131-8.

[6] Lyu H, Zhao H, Tang J, Gong Y, Huang Y, Wu Q, et al. Immobilization of hexavalent chromium in contaminated soils using biochar supported nanoscale iron sulfide composite. Chemosphere. 2018;194:360-9.

[7] Tang WW, Zeng GM, Gong JL, Liang J, Xu P, Zhang C, et al. Impact of humic/fulvic acid on the removal of heavy metals from aqueous solutions using nanomaterials: a review. Sci Total Environ. 2014;468-469:1014-27.

[8] Beretta G, Mastorgio A, Pedrali L, Saponaro S, Sezenna E. Support tool for identifying in situ remediation technology for sites contaminated by hexavalent chromium. Water. 2018;10(10):1344.

[9] Palansooriya KN, Shaheen SM, Chen SS, Tsang DCW, Hashimoto Y, Hou DY, et al. Soil amendments for 
immobilization of potentially toxic elements in contaminated soils: a critical review. Environ Int. 2020;134:10504.

[10] Li X, He X, Wang H, Liu Y. Characteristics and long-term effects of stabilized nanoscale ferrous sulfide immobilized hexavalent chromium in soil. J Hazard Mater. 2020;389:122089.

[11] Su H, Fang Z, Tsang PE, Fang J, Zhao D. Stabilisation of nanoscale zero-valent iron with biochar for enhanced transport and in situ remediation of hexavalent chromium in soil. Environ Pollut. 2016;214:94-100.

[12] Cheng S, Chen T, Xu W, Huang J, Jiang S, Yan B. Application research of biochar for the remediation of soil heavy metals contamination: a review. Molecules. 2020;25:14.

[13] Ma Y, Li F, Jiang Y, Yang W, Lv L, Xue H, et al. Remediation of $\mathrm{Cr}(\mathrm{vI})$-contaminated soil using the acidified hydrazine hydrate. Bull Env Contam Toxicol. 2016;97(3):392-4.

[14] Qiu X, Fang Z, Yan X, Gu F, Jiang F. Emergency remediation of simulated chromium (vi)-polluted river by nanoscale zerovalent iron: laboratory study and numerical simulation. Chem Eng J. 2012;193-194:358-65.

[15] Sedlazeck KP, Vollprecht D, Muller P, Mischitz R, Giere R. Impact of an in situ $\mathrm{Cr}(\mathrm{VI})$-contaminated site remediation on the groundwater. Environ Sci Pollut Res Int. 2020;27(13):14465-75.

[16] Bian X, Cui J, Tang B, Yang L. Chelant-induced phytoextraction of heavy metals from contaminated soils: a review. Pol J Environ Stud. 2018;27(6):2417-24.

[17] Su C, Puls RW. Arsenate and arsenite removal by zerovalent iron: kinetics, redox transformation, and implications for in situ groundwater remediation. Environ Sci \& Technol. 2001;35(7):1487-92.

[18] Xia S, Song Z, Jeyakumar P, Shaheen SM, Rinklebe J, Ok YS, et al. A critical review on bioremediation technologies for $\mathrm{Cr}$ (vi)-contaminated soils and wastewater. Crit Rev Environ Sci Technol. 2019;49(12):1027-78.

[19] Hou S, Wu B, Peng D, Wang Z, Wang Y, Xu H. Remediation performance and mechanism of hexavalent chromium in alkaline soil using multi-layer loaded nano-zero-valent iron. Environ Pollut. 2019;252:553-61.

[20] Song J, Townsend T, Solo-Gabriele H, Jang Y-C. Hexavalent chromium reduction in soils contaminated with chromated copper arsenate preservative. Soil Sediment Contaminat Int J. 2006;15(4):387-99.

[21] Chrysochoou M, Johnston CP, Dahal G. A comparative evaluation of hexavalent chromium treatment in contaminated soil by calcium polysulfide and green-tea nanoscale zero-valent iron. J Hazard Mater. 2012;201-202:33-42.

[22] Zhe Z, Yuxiu A. Nanotechnology for the oil and gas industry - an overview of recent progress. Nanotechnol Rev. 2018;7(4):341-53.

[23] Adebayo EA, Ibikunle JB, Oke AM, Lateef A, Azeez MA, Oluwatoyin $\mathrm{AO}$, et al. Antimicrobial and antioxidant activity of silver, gold and silver-gold alloy nanoparticles phytosynthesized using extract of opuntia ficus-indica. Rev Adv Mater Sci. 2019;58(1):313-26.

[24] Qian L, Shang X, Zhang B, Zhang W, Su A, Chen Y, et al. Enhanced removal of $\mathrm{Cr}(\mathrm{VI})$ by silicon rich biochar-supported nanoscale zero-valent iron. Chemosphere. 2019;215:739-45.

[25] Zhou Y, Wang T, Zhi D, Guo B, Zhou Y, Nie J, et al. Applications of nanoscale zero-valent iron and its composites to the removal of antibiotics: a review. J Mater Sci. 2019;54(19):12171-88.

[26] Singh R, Misra V, Singh RP. Removal of $\mathrm{Cr}(\mathrm{VI})$ by nanoscale zero-valent iron (nZVI) from soil contaminated with tannery wastes. Bull Env Contam Toxicol. 2012;88(2):210-4.

[27] Zou Y, Wang X, Khan A, Wang P, Liu Y, Alsaedi A, et al. Environmental remediation and application of nanoscale zero-valent iron and its composites for the removal of heavy metal ions: a review. Env Sci Technol. 2016;50(14):7290-304.

[28] Das S, Srivastava VC. An overview of the synthesis of CuO-ZnO nanocomposite for environmental and other applications. Nanotechnol Rev. 2018;7(3):267-82.

[29] Sacca ML, Fajardo C, Costa G, Lobo C, Nande M, Martin M. Integrating classical and molecular approaches to evaluate the impact of nanosized zero-valent iron $(\mathrm{nZVI})$ on soil organisms. Chemosphere. 2014;104:184-9.

[30] Fang Z, Chen J, Qiu X, Qiu X, Cheng W, Zhu L. Effective removal of antibiotic metronidazole from water by nanoscale zero-valent iron particles. Desalination. 2011;268(1-3):60-7.

[31] Chekli L, Phuntsho S, Roy M, Shon HK. Characterisation of Fe-oxide nanoparticles coated with humic acid and Suwannee River natural organic matter. Sci Total Env. 2013;461-462:19-27.

[32] Pei G, Zhu Y, Wen J, Pei Y, Li H. Vinegar residue supported nanoscale zero-valent iron: remediation of hexavalent chromium in soil. Env Pollut. 2020;256:113407.

[33] Li J, Liu H, Deng Y, Liu G, Chen Y, Yang J. Emerging nanostructured materials for the catalytic removal of volatile organic compounds. Nanotechnol Rev. 2016;5(1):147-181.

[34] Nemecek J, Lhotsky 0, Cajthaml T. Nanoscale zero-valent iron application for in situ reduction of hexavalent chromium and its effects on indigenous microorganism populations. Sci Total Env. 2014;485-486:739-47.

[35] Crane RA, Scott TB. Nanoscale zero-valent iron: future prospects for an emerging water treatment technology. J Hazard Mater. 2012;211-212:112-25.

[36] Guan X, Sun Y, Qin H, Li J, Lo IMC, He D, et al. The limitations of applying zero-valent iron technology in contaminants sequestration and the corresponding countermeasures: the development in zero-valent iron technology in the last two decades (1994-2014). Water Res. 2015;75:224-48.

[37] Wang C, Baer DR, Amonette JE, Engelhard MH, Antony J, Qiang Y. Morphology and electronic structure of the oxide shell on the surface of iron nanoparticles. J Am Chem Soc. 2009;131(25):8824-32.

[38] Wang S, Gao B, Li Y, Creamer AE, He F. Adsorptive removal of arsenate from aqueous solutions by biochar supported zerovalent iron nanocomposite: batch and continuous flow tests. J Hazard Mater. 2017;322(Pt A):172-81.

[39] Liu X, Yang L, Zhao H, Wang W. Pyrolytic production of zerovalent iron nanoparticles supported on rice huskderived biochar: simple, in situ synthesis and use for remediation of $\mathrm{Cr}(\mathrm{vI})$-polluted soils. Sci Total Environ. 2020;708.

[40] Shan G, Yan S, Tyagi RD, Surampalli RY, Zhang TC. Applications of nanomaterials in environmental science and engineering: review. Pract Periodic Hazard Toxic Radioact Waste Manage. 2009;13(2):110-9. 
[41] Yang F, Zhang S, Sun Y, Cheng K, Li J, Tsang DCW. Fabrication and characterization of hydrophilic corn stalk biochar-supported nanoscale zero-valent iron composites for efficient metal removal. Bioresour Technol. 2018;265:490-7.

[42] Stefaniuk M, Oleszczuk P, Ok YS. Review on nano zerovalent iron (nZVI): from synthesis to environmental applications. Chem Eng J. 2016;287:618-32.

[43] Liu M, Wang Y, Chen L, Zhang Y, Lin Z. $\mathrm{Mg}(\mathrm{OH})_{2}$ supported nanoscale zero valent iron enhancing the removal of $\mathrm{Pb}($ ॥I) from aqueous solution. ACS Appl Mater Interfaces. 2015;7(15):7961-9.

[44] Burda C, Chen X, Narayanan R, El-Sayed MA. Chemistry and properties of nanocrystals of different shapes. Chem Rev. 2005;105(4):1025-102.

[45] Liu X, Dong H, Zeng Q, Yang X, Zhang D. Synergistic effects of reduced nontronite and organic ligands on $\mathrm{Cr}(\mathrm{vI})$ reduction. Env Sci Technol. 2019;53(23):13732-41.

[46] Zhang R, Zhang N, Fang Z. In situ remediation of hexavalent chromium contaminated soil by CMC-stabilized nanoscale zero-valent iron composited with biochar. Water Sci Technol. 2018;77(5-6):1622-31.

[47] Thompson L, Azadmanjiri J, Nikzad M, Sbarski I, Wang J, Yu A. Cellulose nanocrystals: production, functionalization and advanced applications. Rev Adv Mater Sci. 2019;58(1):1-16.

[48] Wang Y, Fang ZQ, Liang B, Tsang EP. Remediation of hexavalent chromium contaminated soil by stabilized nanoscale zero-valent iron prepared from steel pickling waste liquor. Chem Eng J. 2014;247:283-90.

[49] Wang C, Kang J, Liang P, Zhang H, Sun H, Tadé MO, et al. Ferric carbide nanocrystals encapsulated in nitrogen-doped carbon nanotubes as an outstanding environmental catalyst. Environ Sci Nano. 2017;4(1):170-9.

[50] Dong H, Zhang C, Hou K, Cheng Y, Deng J, Jiang Z, et al. Removal of trichloroethylene by biochar supported nanoscale zero-valent iron in aqueous solution. Sep Purif Technol. 2017;188:188-96.

[51] Kustov LM, Finashina ED, Shuvalova EV, Tkachenko OP, Kirichenko OA. Pd-Fe nanoparticles stabilized by chitosan derivatives for perchloroethene dechlorination. Env Int. 2011;37(6):1044-52.

[52] Zhou Y, Gao B, Zimmerman AR, Chen H, Zhang M, Cao X. Biochar-supported zerovalent iron for removal of various contaminants from aqueous solutions. Bioresour Technol. 2014;152:538-42.

[53] Wang H, Zhang M, Li H. Synthesis of nanoscale zerovalent iron ( $\mathrm{nZVI}$ ) supported on biochar for chromium remediation from aqueous solution and soil. Int J Environ Res Public Health. 2019;16(22):4430.

[54] Lin Y, Xu J, Sudhakar BS, Gu J, Hong R. Preparation of spherical aminopropyl-functionalized MCM-41 and its application in removal of $\mathrm{Pb}(\mathrm{II})$ ion from aqueous solution. Nanotechnol Rev. 2019;8(1):275-84.

[55] Liu X-y, Jiao C, Fan W-j, Pan J-m, Cheng Y, Lu M. Synthesis of MCM-41 stabilized NZVI and its use in removal of $\mathrm{Cr}(\mathrm{VI})$ from aqueous solution. J Water Reuse Desalinat. 2015;5(2):149-56.

[56] Chang C, Lian F, Zhu L. Simultaneous adsorption and degradation of $\mathrm{\gamma}-\mathrm{HCH}$ by $\mathrm{nZVI} / \mathrm{Cu}$ bimetallic nanoparticles with activated carbon support. Environ Pollut. 2011;159(10):2507-14.

[57] Wang Y, Zhou D, Wang Y, Zhu X, Jin S. Humic acid and metal ions accelerating the dechlorination of 4-chlorobiphenyl by nanoscale zero-valent iron. J Environ Sci.

2011;23(8):1286-92.

[58] Yao Y, Chen H, Lian C, Wei F, Zhang D, Wu G, et al. Fe, Co, Ni nanocrystals encapsulated in nitrogen-doped carbon nanotubes as Fenton-like catalysts for organic pollutant removal. J Hazard Mater. 2016;314:129-39.

[59] Zhang X, Zhang Y, Tian B, Song K, Liu P, Jia Y, et al. Review of nano-phase effects in high strength and conductivity copper alloys. Nanotechnol Rev. 2019;8(1):383-95.

[60] Ni H, Zhu J, Wang Z, Lv H, Su Y, Zhang X. A brief overview on grain growth of bulk electrodeposited nanocrystalline nickel and nickel-iron alloys. Rev Adv Mater Sci.

2019;58(1):98-106.

[61] Xu D, Song X, Qi W, Wang H, Bian Z. Degradation mechanism, kinetics, and toxicity investigation of 4-bromophenol by electrochemical reduction and oxidation with $\mathrm{Pd}-\mathrm{Fe}$ /graphene catalytic cathodes. Chem Eng J. 2018;333:477-85.

[62] Akhgar BN, Pourghahramani P. Implementation of sonochemical leaching for preparation of nano zero-valent iron (NZVI) from natural pyrite mechanochemically reacted with Al. Int J Miner Process. 2017;164:1-5.

[63] Han W, Fu F, Cheng Z, Tang B, Wu S. Studies on the optimum conditions using acid-washed zero-valent iron/aluminum mixtures in permeable reactive barriers for the removal of different heavy metal ions from wastewater. J Hazard Mater. 2016;302:437-46.

[64] Zhu F, Li L, Ma S, Shang Z. Effect factors, kinetics and thermodynamics of remediation in the chromium contaminated soils by nanoscale zero valent $\mathrm{Fe} / \mathrm{Cu}$ bimetallic particles. Chem Eng J. 2016;302:663-9.

[65] Leupin OX, Hug SJ. Oxidation and removal of arsenic (III) from aerated groundwater by filtration through sand and zerovalent iron. Water Res. 2005;39(9):1729-40.

[66] Liu SC, Gao HJ, Cheng R, Wang YJ, Ma XL, Peng C, et al. Study on influencing factors and mechanism of removal of $\mathrm{Cr}(\mathrm{VI})$ from soil suspended liquid by bentonite-supported nanoscale zero-valent iron. Sci Rep. 2020;10(1):8831.

[67] Wang Y, Fang ZQ, Kang Y, Tsang EP. Immobilization and phytotoxicity of chromium in contaminated soil remediated by CMC-stabilized nZVI. J Hazard Mater. 2014;275:230-7.

[68] Hu Y, Xue Q, Tang J, Fan X, Chen H. New insights on $\operatorname{Cr}(\mathrm{vI})$ retention by ferrihydrite in the presence of $\mathrm{Fe}(\mathrm{II})$.

Chemosphere. 2019;222:511-6.

[69] Zhu S, Huang X, Wang D, Wang L, Ma F. Enhanced hexavalent chromium removal performance and stabilization by magnetic iron nanoparticles assisted biochar in aqueous solution: mechanisms and application potential. Chemosphere. 2018;207:50-9.

[70] Diao ZH, Du JJ, Jiang D, Kong LJ, Huo WY, Liu CM, et al. Insights into the simultaneous removal of $\mathrm{Cr}(6+)$ and $\mathrm{Pb}(2+)$ by a novel sewage sludge-derived biochar immobilized nanoscale zero valent iron: coexistence effect and mechanism. Sci Total Environ. 2018;642:505-15.

[71] Li X-q, Cao J, Zhang W-x. Stoichiometry of $\operatorname{Cr}(\mathrm{vI})$ immobilization using nanoscale zerovalent iron (nZVI): a study with 
high-resolution X-ray photoelectron spectroscopy (HR-XPS). Ind Eng Chem Res. 2008;47(7):2131-9.

[72] Zhang Y, Li Y, Zheng X. Removal of atrazine by nanoscale zero valent iron supported on organobentonite. Sci Total Environ. 2011;409(3):625-30.

[73] Fajardo C, Gil-Diaz M, Costa G, Alonso J, Guerrero AM, Nande M, et al. Residual impact of aged nZVI on heavy metalpolluted soils. Sci Total Environ. 2015;535:79-84.

[74] Wang Y, O'Connor D, Shen Z, Lo IMC, Tsang DCW, Pehkonen $S$, et al. Green synthesis of nanoparticles for the remediation of contaminated waters and soils: constituents, synthesizing methods, and influencing factors. J Clean Prod. 2019;226:540-9.

[75] Shu YR, Ji B, Cui BH, Shi YT, Wang J, Hu M, et al. Almond shell-derived, biochar-supported, nano-zero-valent iron composite for aqueous hexavalent chromium removal: performance and mechanisms. Nanomaterials. 2020;10:2.

[76] Doğaroğlu ZG, Kantar C. Reductive immobilization of chromium in soils containing heterogeneous Fe-bearing minerals. Soil Sediment Contaminat Int J. 2016;25(8):857-67.

[77] Xu T, Nan F, Jiang XF, Tang YL, Zeng YH, Zhang WH, et al. Effect of soil $\mathrm{pH}$ on the transport, fractionation, and oxidation of chromium(III). Ecotoxicol Environ Saf. 2020;195:110459.

[78] Su H, Fang Z, Tsang PE, Zheng L, Cheng W, Fang J, et al. Remediation of hexavalent chromium contaminated soil by biochar-supported zero-valent iron nanoparticles. J Hazard Mater. 2016;318:533-40.

[79] Ossai Cl, Raghavan N. Nanostructure and nanomaterial characterization, growth mechanisms, and applications. Nanotechnol Rev. 2018;7(2):209-31.

[80] Choe S, Chang Y-Y, Hwang K-Y, Khim J. Kinetics of reductive denitrification by nanoscale zero-valent iron. Chemosphere. 2000;41(8):1307-11.

[81] Sun YK, Li JX, Huang TL, Guan XH. The influences of iron characteristics, operating conditions and solution chemistry on contaminants removal by zero-valent iron: a review. Water Res. 2016;100:277-95.

[82] Kanel SR, Manning B, Charlet L, Choi H. Removal of arsenic (III) from groundwater by nanoscale zero-valent iron. Environ Sci Technol. 2005;39(5):1291-8.

[83] Di Palma L, Verdone N, Vilardi G. Kinetic modeling of $\mathrm{Cr}(\mathrm{vI})$ reduction by $n Z V I$ in soil: the influence of organic matter and manganese oxide. Bull Environ Contam Toxicol. 2018;101(6):692-7.

[84] Tran HN, Nguyen DT, Le GT, Tomul F, Lima EC, Woo SH, et al. Adsorption mechanism of hexavalent chromium onto layered double hydroxides-based adsorbents: a systematic in-depth review. J Hazard Mater. 2019;373:258-70.

[85] Lv X, Xue X, Jiang G, Wu D, Sheng T, Zhou H, et al. Nanoscale zero-valent iron (nZVI) assembled on magnetic $\mathrm{Fe}_{3} \mathrm{O}_{4} /$ graphene for chromium( $\mathrm{VI}$ ) removal from aqueous solution. J Colloid Interface Sci. 2014;417:51-59.

[86] Shu HY, Chang MC, Yu HH, Chen WH. Reduction of an azo dye acid black 24 solution using synthesized nanoscale zerovalent iron particles. J Colloid Interface Sci. 2007;314(1):89-97.

[87] Joo SH, Feitz AJ, Sedlak DL, Waite TD. Quantification of the oxidizing capacity of nanoparticulate zero-valent iron. Environ Sci Technol. 2005;39(5):1263-8.
[88] Di Palma L, Gueye MT, Petrucci E. Hexavalent chromium reduction in contaminated soil: a comparison between ferrous sulphate and nanoscale zero-valent iron. J Hazard Mater. 2015;281:70-6.

[89] Ma X, Gurung A, Deng Y. Phytotoxicity and uptake of nanoscale zero-valent iron (nZVI) by two plant species. Sci Total Environ. 2013;443:844-9.

[90] Zhang J, Hao Z, Zhang Z, Yang Y, Xu X. Kinetics of nitrate reductive denitrification by nanoscale zero-valent iron. Proc Saf Environ Protect. 2010;88(6):439-45.

[91] Pei G, Zhu Y, Wen J, Pei Y, Li H. Vinegar residue supported nanoscale zero-valent iron: remediation of hexavalent chromium in soil. Environ Pollut. 2020;256:113407.

[92] Yi Z, Tang Q, Jiang T, Cheng Y. Adsorption performance of hydrophobic/hydrophilic silica aerogel for low concentration organic pollutant in aqueous solution. Nanotechnol Rev. 2019;8(1):266-74.

[93] Ahmadi M, Elmongy H, Madrakian T, Abdel-Rehim M. Nanomaterials as sorbents for sample preparation in bioanalysis: review. Anal Chim Acta. 2017;958:1-21.

[94] Yusmartini ES, Ridwan, Setiabudidaya D, Faizal M. Marsi, Synthesis and characterizations of nZVI-AC composites from coconut shells and its application for the adsorption of $\mathrm{Pb}(\mathrm{II})$ and $\mathrm{Cr}(\mathrm{VI})$ ions. IOP Conf Ser Mater Sci Eng. 2019;509:012042.

[95] Khin MM, Nair AS, Babu VJ, Murugan R, Ramakrishna S. A review on nanomaterials for environmental remediation. Energy Environ Sci. 2012;5(8):8075-109.

[96] Li J, Chen CL, Zhu KR, Wang XK. Nanoscale zero-valent iron particles modified on reduced graphene oxides using a plasma technique for Cd(II) removal. J Taiwan Inst Chem Eng. 2016;59:389-94.

[97] Wang C, Luo H, Zhang Z, Wu Y, Zhang J, Chen S. Removal of $\mathrm{As}(\mathrm{III})$ and $\mathrm{As}(\mathrm{v})$ from aqueous solutions using nanoscale zero valent iron-reduced graphite oxide modified composites. J Hazard Mater. 2014;268:124-31.

[98] Bhowmick S, Chakraborty S, Mondal P, Van Renterghem W, Van den Berghe S, Roman-Ross G, et al. Montmorillonitesupported nanoscale zero-valent iron for removal of arsenic from aqueous solution: kinetics and mechanism. Chem Eng J. 2014;243:14-23.

[99] Sharma AK, Kumar R, Mittal S, Hussain S, Arora M, Sharma RC, et al. In situ reductive regeneration of zerovalent iron nanoparticles immobilized on cellulose for atom efficient $\mathrm{Cr}(\mathrm{vI})$ adsorption. RSC Adv. 2015;5(109):89441-6.

[100] De Gisi S, Lofrano G, Grassi M, Notarnicola M. Characteristics and adsorption capacities of low-cost sorbents for wastewater treatment: a review. Sustain Mater Technol. 2016;9:10-40.

[101] Peng Z, Xiong C, Wang W, Tan F, Xu Y, Wang X, et al. Facile modification of nanoscale zero-valent iron with high stability for $\mathrm{Cr}(\mathrm{VI})$ remediation. Sci Total Environ. 2017;596-597:266-73.

[102] Saif S, Tahir A, Chen Y. Green synthesis of iron nanoparticles and their environmental applications and implications. Nanomaterials. 2016;6(11):209.

[103] Wan Z, Cho DW, Tsang DCW, Li M, Sun T, Verpoort F. Concurrent adsorption and micro-electrolysis of $\mathrm{Cr}(\mathrm{vI})$ by nanoscale zerovalent iron/biochar/Ca-alginate composite. Environ Pollut. 2019;247:410-20. 
[104] Wu Y, Pang H, Liu Y, Wang X, Yu S, Fu D, et al. Environmental remediation of heavy metal ions by novel-nanomaterials: a review. Environ Pollut. 2019;246:608-20.

[105] Reginatto C, Cecchin I, Heineck KS, Reddy KR, Thome A. Use of nanoscale zero-valent iron for remediation of clayey soil contaminated with hexavalent chromium: batch and column tests. Int J Environ Res Public Health. 2020;17(3):1001.

[106] Chen P-J, Su C-H, Tseng C-Y, Tan S-W, Cheng C-H. Toxicity assessments of nanoscale zerovalent iron and its oxidation products in medaka (Oryzias latipes) fish. Mar Pollut Bull. 2011;63(5-12):339-46.

[107] Liu W, Jin L, Xu J, Liu J, Li Y, Zhou P, et al. Insight into pH dependent $\mathrm{Cr}(\mathrm{vI})$ removal with magnetic $\mathrm{Fe}_{3} \mathrm{~S}_{4}$. Chem Eng J. 2019;359:564-71.

[108] Fajardo C, Ortiz LT, Rodriguez-Membibre ML, Nande M, Lobo MC, Martin M. Assessing the impact of zero-valent iron (ZVI) nanotechnology on soil microbial structure and functionality: a molecular approach. Chemosphere. 2012;86(8):802-8.

[109] Jiang DN, Zeng GM, Huang DL, Chen M, Zhang C, Huang C, et al. Remediation of contaminated soils by enhanced nanoscale zero valent iron. Environ Res. 2018;163:217-27.

[110] Qiu X, Fang Z, Yan X, Cheng W, Lin K. Chemical stability and toxicity of nanoscale zero-valent iron in the remediation of chromium-contaminated watershed. Chem Eng J. 2013;220:61-6.

[111] El-Temsah YS, Joner EJ. Ecotoxicological effects on earthworms of fresh and aged nano-sized zero-valent iron (nZVI) in soil. Chemosphere. 2012;89(1):76-82.

[112] Lefevre E, Bossa N, Wiesner MR, Gunsch CK. A review of the environmental implications of in situ remediation by nanoscale zero valent iron (nZVI): behavior, transport and impacts on microbial communities. Sci Total Environ. 2016;565:889-901. 